\title{
Reform Thinking of Strengthening Students' Ability Training in the Practice of Descriptive Geometry and Mechanical Drawing Course
}

\author{
Xiaohao $\mathrm{Li}^{*}$, Mingxu Ma

\begin{abstract}
School of Mechanical Engineering and Automation, Northeastern University, Shenyang Liaoning 110819, P.R. China *Corresponding author
\end{abstract}

\begin{abstract}
The education and teaching of the descriptive geometry and mechanical drawing course is responsible for the training of the expression ability and spatial image thinking ability of the full-time engineering undergraduate and related professional engineering technicians. Based on the teaching experience of the authors who have worked in the front-line courses many years and the current teaching situation of the course, this paper holds that the teaching work of the course should be based on the classroom teaching, combined with the teaching experience, practical experience and engineering design application experience of the industry experts. To carry out the integration and development of the multi-disciplinary thought, philosophical thought and aesthetic thought in the education and teaching of descriptive geometry and mechanical drawing courses. And to explore how to improve students' theoretical knowledge and practical skills at the same time, and think about to promote students' theoretical level and application ability in a win-win situation.
\end{abstract}

Keywords: Component descriptive geometry, Cartographic practice, Training of students' ability

\section{INTRODUCTION}

The education and teaching of the engineering graphics course is responsible for the training of the expression ability and spatial image thinking ability of the engineering technicians in the engineering full-time undergraduate course and related majors. With the development of society and the progress of science and technology, mechanical engineering drawing has undergone great changes in its expression and drawing methods. From the original pure manual drawing to the coexistence of manual drawing and computer drawing, the coexistence of two-dimensional engineering drawing and three-dimensional entity design drawing, to the computer two-dimensional basically replacing manual drawing, and the three-dimensional entity design drawing has greatly surpassed and replaced the two-dimensional engineering The potential of a graph [1]. In the outline of the national medium and long term education reform and development plan, it is mentioned that "to meet the needs of national and regional economic and social development, we should establish a dynamic adjustment mechanism and constantly optimize the structure of higher education. Optimize the discipline, type, and level structure, and promote the interdisciplinary and integration. We will focus on expanding the training of applied, compound and skilled personnel." [2]. All disciplines of engineering should conduct extensive and in-depth research on the types, levels, current situation and future prediction of talent demand through extensive and in-depth research on relevant disciplines and enterprises, so as to realize the docking of talent training and social demand.

The teaching of Engineering Graphics Course in higher education should be based on the characteristics of the object to be accepted, strengthen the centralized classroom teaching, teach students according to their aptitude, pay attention to the training and improvement of students' practical skills, so that the trained professional and technical talents based on the knowledge system of Engineering Graphics can meet the continuous development of social needs "[3]. Therefore, how to effectively use the limited classroom teaching time to complete the teaching content of descriptive geometry and mechanical drawing courses, so that students can learn to apply, for the teachers engaged in engineering graphics course teaching must think about the important issues to be solved. According to the current situation of curriculum teaching, it is considered that the integration and development of multi-disciplinary ideas such as subject thought, mathematics thought, philosophy thought and aesthetic thought should be carried out in-depth based on the classroom teaching and combined with the teaching experience, practical experience and engineering design application experience of everyone in the industry. Explore how to improve students' theoretical knowledge level and practical skills at the same time, and think about how to promote students' theoretical level and application ability in a win-win situation. 


\section{STRENGTHEN THE CULTIVATION OF STUDENTS' COMPREHENSIVE THEORETICAL ABILITY}

Classroom teaching is an important way to cultivate students' abilities. In the teaching of descriptive geometry and a mechanical drawing, we should take classroom teaching as an opportunity, take knowledge teaching as a carrier, and create an equal and loose classroom environment for the audience students [4]. From the preparation of teaching plans, the implementation of teaching contents to the examination of courses, teachers actively interact with students in the classroom, actively guide students to think, encourage students to put forward questions bravely, answer students' questions creatively, and inspire students' academic thinking to create equal interaction [5]. Through induction, comparison and summary, the course teachers should make the theoretical knowledge of descriptive geometry and the practical content of mechanical drawing an organic whole, so as to facilitate the students to master and apply them. As known, when talking about the projection characteristics of straight lines, which are very important knowledge points in the course of descriptive geometry and a mechanical drawing, teachers can present the properties, methods and use problems related to straight lines to students, according to their mastery of knowledge, which is not only convenient for students to grasp the knowledge points related to straight line projection as a whole, but also can promote students to based on comprehensive understanding, this paper extends how to make good use of these knowledge points and how to use them to creatively analyze and solve problems.

In recent years, from the perspective of students' learning of descriptive geometry and a mechanical drawing course, students' innovative ability comes from innovative thinking, while innovative thinking comes from the active guidance of teaching teachers, which requires drawing teachers to collect and sort out vivid cases, develop classroom teaching mode to guide students to think actively and explore, and teachers in classroom should also according to drawing methods, skills and other contents It can provide enough space for students' innovation ability, guide students to design and raise questions, discuss problems through positive thinking, encourage students to argue and identify, and clarify the root causes of problems. Cultivate students' independent learning ability and thinking ability.

\section{STRENGTHEN THE CULTIVATION OF STUDENTS' COMPREHENSIVE APPLICATION ABILITY}

In the course of descriptive geometry and drawing, the traditional teaching arrangement of mechanical drawing content mainly adopts manual drawing operation, which requires special drawing classroom, drawing board, t-ruler and other necessary conditions for drawing. Nowadays, computer drawing has been widely used in mechanical design [6]. In view of the students' strong learning and operating ability of computer drawing software, and in combination with the requirements of colleges and enterprises for drawing application ability, we have explored how to combine the manual ruler drawing and computer drawing in the traditional drawing practice. In the classroom, through the detailed explanation of typical mechanical parts and interspersed with some machining videos, the content of the drawings and its role in the production practice are explained, to increase the students' understanding of the process knowledge of parts processing and parts installation, improve the perceptual knowledge of the production practice, and consolidate the theoretical knowledge of mechanical drawing to a certain extent. In the classroom, students are guided to conduct manual mapping and sketch by groups against the actual parts, so that students can not only master the correct use of measurement tools, but also have a deeper understanding of the content of parts drawings, gradually master the view expression of parts and parts drawings and the optimization of expression scheme, consolidate the knowledge content of parts expression method and how to apply it flexibly to practical problems. Then through the drawing software to express the features of parts quickly and accurately, through the teaching practice of parts drawing which highlights practical skills in recent years, from the feedback results, it has achieved good skills training effect.

\section{STRENGTHEN THE ENGINEERING QUALITY TRAINING IN THE TEACHING OF THE COURSE PRACTICE LINK}

The practice of descriptive geometry and mechanical drawing is the subject content of combining theory with practice to cultivate students' ability to solve practical engineering problems. In the whole process of measurement and drawing, students observe, analyze and think through parts. Teachers also need to guide students to understand the difference of theoretical knowledge between engineering drawing and ordinary mechanical drawing, and have a process structure that meets the requirements of design, processing and assembly. It has been proved that students know nothing about machines, parts and engineering drawings, and go through a stage of learning, especially through the practice of mechanical drawing and mapping, so that each student can independently complete the parts mapping, and the engineering consciousness is strengthened, so as to further improve the engineering consciousness and engineering ability [7].

Teaching practice shows that the whole surveying and mapping process should focus on the expression scheme, dimension and technical requirements of the view from the production reality. Engineering drawing course is one of the first courses for college students to learn after entering the University. Through surveying and mapping practice and computer drawing practice, it further emphasizes the basic 
concept of engineering design, understands and gradually grasps the relevant thoughts and methods of modern engineering design, and introduces advanced design concepts and design means to students, pointing out the direction for future study. In addition, in the teaching, we should pay attention to the implementation of drawing standards, at the same time, we should pay attention to the consistency between the benchmark of parts and the matching size and associated size of related parts, and round the size to make the size standardized, normalized and serialized.

\section{STRENGTHEN THE MANAGEMENT OF TEACHING ORGANIZATION}

The complete practical teaching syllabus and experimental teaching materials of descriptive geometry and mechanical drawing have been established. In each operation link of Surveying and mapping and instrument diagram in the course of practical teaching, it is necessary to make the practical tasks clear and achieve specific goals. In each stage of practical teaching, corresponding learning objectives, contents, key and difficult points, and evaluation indexes of the course knowledge points should be prepared. In the process of practical operation, teachers should set up corresponding teaching strategies to fully mobilize students' initiative and initiative in learning, encourage some students with solid foundation and high theoretical level to design relevant practical operation process according to their own academic level with the help of relevant instruments and equipment in the laboratory, actively explore, cultivate and improve their self-learning ability. Teachers and teaching managers should actively improve the practical teaching management system, explore the establishment of a leading group of practical teaching reform of basic professional technology courses, and plan the practical teaching links from a macro perspective. Establish a teaching quality supervision group to inspect and evaluate practical teaching, supervise and standardize the implementation process of practical operation and the evaluation of practical teaching process, as well as the evaluation of practical teaching effect. According to the actual situation of our school, the course teaching team has formulated a perfect evaluation standard for the quality of practical teaching links in descriptive geometry and mechanical drawing courses, improved the operation management system of middle school students in practical teaching, and further clarified the guidance responsibility of the teachers in practical teaching. Through the cross flow of teachers and experimenters, the open laboratory system has been established we have set up the detailed rules of innovation design and bonus points to guide the practical teaching activities. From the relevant practical teaching achievements, we have achieved very good results in our school.

In the practical teaching activities of descriptive geometry and mechanical drawing course in our school, the teaching team of the course, based on the investigation of many years' students' practical achievements and the analysis of the achievement degree of practical training objectives, fully tap the practical operation potential of the teaching students, pay attention to the stimulation of students' interest in learning in the teaching process, and establish the practical teaching method of the course through the summary and discussion of teachers' practical teaching experience From indoctrination to initiative learning mode. At the same time, the teachers make full use of their spare time to carry out the training mode of the operating assistant in the practical teaching of the course, encourage the individualized training of the audience students, encourage the students to participate in various innovation activities related to the course content and ability, provincial and national level competition projects based on the course learning, and at the same time, reward the credits according to the activities. On the basis of practical teaching of descriptive geometry and mechanical drawing courses, teachers of professional basic courses and professional courses shall be organized to arrange all kinds of practical teaching and course design for students in the undergraduate stage as a whole. At the same time, encourage some students who have a good foundation and spare no effort to help teachers to build the laboratory and participate in the development of new experimental content, and participate in the daily management and maintenance of the laboratory. Teaching quality is the lifeline of colleges and universities. It is an inevitable trend for the development of higher education to cultivate innovative talents who can quickly adapt to the needs of society, have strong adaptability, solid theoretical knowledge and strong practical skills.

\section{SUMMARY}

According to the characteristics of the teaching of descriptive geometry and mechanical drawing, this paper carried out the reform and thinking of teaching and learning methods, which emphasized the training of students comprehensive ability and practical skills, and achieved the obvious effect of teaching reform. Through the combination of theoretical knowledge learning and the skillful application of drawing software, not only the students' drawing and reading ability were improved, but also the students were led to develop the correct and high level effective thinking mode of engineering graphics and standardizing the process of solving practical problems play an important role.

\section{ACKNOWLEDGEMENT}

This research was supported by Education and Teaching Reform Project of Liaoning Province, China (No. [2018] 471 Letter from Liaoning Education Department) and Education and 
Teaching Reform Project of Northeastern University of China (No. [2018] 39 Teaching Documents of Northeastern University).

\section{REFERENCES}

[1] Q.N. Hu, F. Gao, X.F. Wang, H. Shu, D.L. Wang, The engineering graphics education reform based on the comprehensive development of students, J. Eng. Graph. 4 (2006) 134-137.

[2] M. Guo, Reflection on the aesthetic education and university students' innovation ability, Meitan High. Educ. 25 (2007) 91-93.

[3] Z.J. Sang, Mechanical drawing design and practice inquiry of computer aided drafting, Heilongjiang Sci. 7 (2016) 38-42.

[4] X.D. Yang, Reconstruction of teaching system of modern engineering graphics for machinery speciality, Vocat. Tech. Educ. (Educ. Sci.) 23 (2002) 35-37.

[5] M.H. Shen, Consideration on the development of mechanical laboratory in independent college, Exp. Tech. Manage. 24 (2007) 138-140.

[6] M.L. Zhang, Some thoughts for the engineering graphics education, J. Donghua Univ. (Nat. Sci.) 36 (2010) 473-476.

[7] D.J. Tao, D.G. Ke, D. Li, X. Zhang, On course teaching of engineering graphics based on digitalization, High. Educ. Sci. 117 (2014) 113-117. 